Nardhy Gomez-Lopez*, Roberto Romero*, Eli Maymon, Juan Pedro Kusanovic, Bogdan Panaitescu, Derek Miller, Percy Pacora, Adi L. Tarca, Kenichiro Motomura, Offer Erez, Eunjung Jung, Sonia S. Hassan and Chaur-Dong Hsu

\title{
Clinical chorioamnionitis at term IX: in vivo evidence of intra-amniotic inflammasome activation
}

https://doi.org/10.1515/jpm-2018-0271

Received August 15, 2018; accepted September 6, 2018; previously published online November 9, 2018

\begin{abstract}
Background: The inflammasome has been implicated in the mechanisms that lead to spontaneous labor at term. However, whether the inflammasome is activated in the amniotic cavity of women with clinical chorioamnionitis at term is unknown. Herein, by measuring extracellular ASC [apoptosis-associated speck-like protein containing a C-terminal caspase recruitment domain (CARD)], we investigated whether there is in vivo inflammasome activation in amniotic fluid of patients with clinical chorioamnionitis at term with sterile intra-amniotic inflammation and in those with intra-amniotic infection.
\end{abstract}

*Corresponding authors: Nardhy Gomez-Lopez, PhD, Department of Obstetrics and Gynecology, Wayne State University School of Medicine, 275 E. Hancock, Detroit, MI 48201, USA; Perinatology Research Branch, Division of Obstetrics and Maternal-Fetal Medicine, Division of Intramural Research, Eunice Kennedy Shriver National Institute of Child Health and Human Development, National Institutes of Health, U.S. Department of Health and Human Services, Bethesda, MD, and Detroit, MI, USA; and Department of Immunology, Microbiology and Biochemistry, Wayne State University School of Medicine, Detroit, MI, USA, Tel.: +(313) 577-8904, E-mail: nardhy.gomez-lopez@wayne.edu, ngomezlo@med.wayne.edu; and Roberto Romero, MD, D. Med. Sci., Perinatology Research Branch, NICHD/NIH/DHHS, Hutzel Women's Hospital, 3990 John R, Box 4, Detroit, MI 48201, USA; Perinatology Research Branch, Division of Obstetrics and Maternal-Fetal Medicine, Division of Intramural Research, Eunice Kennedy Shriver National Institute of Child Health and Human Development, National Institutes of Health, U.S. Department of Health and Human Services, Bethesda, MD, and Detroit, MI, USA; Department of Obstetrics and Gynecology, University of Michigan, Ann Arbor, MI, USA; Department of Epidemiology and Biostatistics, Michigan State University, East Lansing, MI, USA; and Center for Molecular Medicine and Genetics, Wayne State University, Detroit, MI, USA, Tel.: +(313) 993-2700, Fax: +(313) 993-2694, E-mail: prbchiefstaff@med.wayne.edu Eli Maymon, Bogdan Panaitescu, Derek Miller, Percy Pacora, Adi L. Tarca, Kenichiro Motomura, Offer Erez and Eunjung Jung: Perinatology Research Branch, Division of Obstetrics and Maternal-Fetal Medicine,
Methods: This was a retrospective cross-sectional study that included amniotic fluid samples collected from 76 women who delivered after spontaneous term labor with diagnosed clinical chorioamnionitis. Intra-amniotic inflammation was defined as an elevated amniotic fluid interleukin (IL)-6 concentration $\geq 2.6 \mathrm{ng} / \mathrm{mL}$, and intraamniotic infection was diagnosed by the presence of microbial invasion of the amniotic cavity (MIAC) accompanied by intra-amniotic inflammation. Patients were classified into the following groups: (1) women without intra-amniotic inflammation or infection $(n=16)$; (2) women with MIAC but without intra-amniotic inflammation ( $n=5)$; (3) women with sterile intra-amniotic inflammation $(\mathrm{n}=15)$; and (4) women with intra-amniotic infection $(\mathrm{n}=40)$. As a readout of in vivo inflammasome activation, extracellular ASC was measured in

Division of Intramural Research, Eunice Kennedy Shriver National Institute of Child Health and Human Development, National Institutes of Health, U.S. Department of Health and Human Services, Bethesda, MD, and Detroit, MI, USA; and Department of Obstetrics and Gynecology, Wayne State University School of Medicine, Detroit, MI, USA Juan Pedro Kusanovic: Perinatology Research Branch, Division of Obstetrics and Maternal-Fetal Medicine, Division of Intramural Research, Eunice Kennedy Shriver National Institute of Child Health and Human Development, National Institutes of Health, U.S. Department of Health and Human Services, Bethesda, MD, and Detroit, MI, USA; Division of Obstetrics and Gynecology, Faculty of Medicine, Pontificia Universidad Católica de Chile, Santiago, Chile; and Center for Research and Innovation in Maternal-Fetal Medicine (CIMAF), Department of Obstetrics and Gynecology, Sótero del Río Hospital, Santiago, Chile

Sonia S. Hassan: Perinatology Research Branch, Division of Obstetrics and Maternal-Fetal Medicine, Division of Intramural Research, Eunice Kennedy Shriver National Institute of Child Health and Human Development, National Institutes of Health, U.S. Department of Health and Human Services, Bethesda, MD, and Detroit, MI, USA; Department of Obstetrics and Gynecology, Wayne State University School of Medicine, Detroit, MI, USA; and Department of Physiology, Wayne State University School of Medicine, Detroit, MI, USA

Chaur-Dong Hsu: Department of Obstetrics and Gynecology, Wayne State University School of Medicine, Detroit, MI, USA 
amniotic fluid by enzyme-linked immunosorbent assay. Acute inflammatory responses in the amniotic fluid and placenta were also evaluated.

Results: In clinical chorioamnionitis at term: (1) amniotic fluid concentrations of ASC (extracellular ASC is indicative of in vivo inflammasome activation) and IL-6 were greater in women with intra-amniotic infection than in those without intra-amniotic inflammation, regardless of the presence of MIAC; (2) amniotic fluid concentrations of ASC and IL-6 were also higher in women with sterile intra-amniotic inflammation than in those without intra-amniotic inflammation, regardless of the presence of MIAC; (3) amniotic fluid concentrations of IL-6, but not ASC, were more elevated in women with intra-amniotic infection than in those with sterile intra-amniotic inflammation; (4) a positive and significant correlation was observed between amniotic fluid concentrations of ASC and IL-6; (5) no differences were observed in amniotic fluid ASC and IL- 6 concentrations between women with and without MIAC in the absence of intra-amniotic inflammation; (6) women with intraamniotic infection had elevated white blood cell counts and reduced glucose levels in amniotic fluid compared to the other three study groups; and (7) women with intra-amniotic infection presented higher frequencies of acute maternal and fetal inflammatory responses in the placenta than those with sterile intra-amniotic inflammation.

Conclusion: The intra-amniotic inflammatory response, either induced by alarmins or microbes, is characterized by the activation of the inflammasome - as evidenced by elevated amniotic fluid concentrations of extracellular ASC - in women with clinical chorioamnionitis at term. These findings provide insight into the intra-amniotic inflammatory response in women with clinical chorioamnionitis at term.

Keywords: alarmins; amniotic fluid; ASC; cytokine; DAMPs; danger signals; interleukin $1 \beta$ (IL-1 $\beta$ ); interleukin-6 (IL-6); intra-amniotic infection; microbial invasion of the amniotic cavity (MIAC); neutrophils; NLRP3; parturition; PYCARD; sterile intra-amniotic inflammation.

\section{Introduction}

Clinical chorioamnionitis is the most common infectionrelated diagnosis made in labor and delivery units worldwide [1-4]. The standard clinical definition refers to the presence of maternal fever associated with clinical signs (foul-smelling discharge, uterine tenderness, maternal and fetal tachycardia) as well as laboratory abnormalities (i.e. leukocytosis $[5,6])$. Clinical chorioamnionitis at term is associated with adverse maternal events $[2,7,8]$ and increased maternal admission to the intensive care unit $[2,9]$. Importantly, neonates born to mothers with clinical signs of chorioamnionitis have a high risk of neonatal mortality [4] in addition to short- and long-term complications such as neonatal sepsis [10-14], meconium aspiration syndrome [15-18], stillbirth [19, 20], and neurodevelopmental disorders including cerebral palsy [21-31].

Clinical chorioamnionitis was originally thought to occur as a result of the inflammation initiated by microbial invasion of the amniotic cavity (MIAC) [32-39]. However, recent studies have shown that only $60 \%$ of patients with the diagnosis of clinical chorioamnionitis at term have proven intra-amniotic infection using culture or molecular microbiologic techniques; the remaining patients have a maternal systemic inflammatory response (fever) either in the absence of intraamniotic inflammation, MIAC without intra-amniotic inflammation, or intra-amniotic inflammation without demonstrable microorganisms [40], which is referred to as sterile intra-amniotic inflammation [41-45].

Among patients with clinical chorioamnionitis at term, the inflammatory responses in the amniotic fluid [46], cord blood [47] and maternal circulation [48] are similar between those with sterile intra-amniotic inflammation and those with intra-amniotic infection. These data suggest that similar to microbes, danger signals or alarmins, which are mediators initiating sterile inflammation [49-51], can activate similar inflammatory pathways in the amniotic cavity. Our recent studies have shown that, in the context of preterm and term labor, the mechanisms that lead to both sterile intra-amniotic inflammation and intra-amniotic infection involve the inflammasome [52-57]. However, whether the inflammasome is activated in the amniotic cavity of women with clinical chorioamnionitis at term is unknown.

Inflammasomes are cytoplasmic multiprotein complexes that, upon activation, induce the autocatalytic cleavage of pro-caspase-1 into its active form which, in turn, can cleave the inflammatory cytokines pro-interleukin (IL)-1 $\beta$ and pro-IL-18 into their mature and secreted bioactive forms [58-72]. Inflammasome activation can be measured by the detection of the adaptor protein ASC [apoptosis-associated speck-like protein containing a C-terminal caspase recruitment domain (CARD)] in the extracellular space [73-75]. Therefore, the detection of extracellular ASC in biological fluids (e.g. amniotic fluid) 
is considered an in vivo determination of inflammasome activation $[56,57]$.

In the study herein, we measured extracellular ASC to investigate whether there is in vivo inflammasome activation in amniotic fluid of patients with clinical chorioamnionitis at term with sterile intra-amniotic inflammation and in those with intra-amniotic infection.

\section{Materials and methods}

\section{Study design}

This was a retrospective cross-sectional study conducted by querying our clinical database and bank of biological samples of the Perinatology Research Branch, an intramural program of the Eunice Kennedy Shriver National Institute of Child Health and Human Development (NICHD), National Institutes of Health, U.S. Department of Health and Human Services. The Institutional Review Boards of Wayne State University, NICHD, and the Sótero del Rio Hospital in Santiago, Chile, approved the use of samples and biological specimens as well as the use of clinical data for research purposes.

\section{Clinical definitions}

Clinical chorioamnionitis was diagnosed by the presence of maternal fever (temperature $>37.8^{\circ} \mathrm{C}$ ) accompanied by two or more of the following criteria: (1) uterine tenderness, (2) foul-smelling amniotic fluid, (3) fetal tachycardia (heart rate $>160$ beats/min), (4) maternal tachycardia (heart rate $>100$ beats/min), and (5) maternal leukocytosis (leukocyte count $>15,000$ cells $/ \mathrm{mm}^{3}$ ) $[5,6,32,33,76,77]$.
Microbial invasion of the amniotic cavity was defined as a positive amniotic fluid culture and/or polymerase chain reaction with electrospray ionization mass spectrometry (PCR/ESI-MS) (Ibis ${ }^{\circledR}$ Technology-Athogen, Carlsbad, CA, USA) test result [40, 78-81]. Intra-amniotic inflammation was defined as an amniotic fluid IL-6 concentration $\geq 2.6 \mathrm{ng} / \mathrm{mL}$ [82-84]. Sterile intra-amniotic inflammation was defined as an amniotic fluid IL- 6 concentration $\geq 2.6 \mathrm{ng} / \mathrm{mL}$ [82] without microorganisms detected by culture or PCR/ESI-MS $[40,41,43-48,85,86]$. Intra-amniotic infection (or microbial-associated intra-amniotic inflammation) was defined as the presence of MIAC together with intra-amniotic inflammation [40, 41, 43-48, 85-89].

\section{Study population}

This study included amniotic fluid samples collected from 76 women who delivered after spontaneous term labor with diagnosed clinical chorioamnionitis. Patients were classified into the following groups (Table 1): (1) women without intra-amniotic inflammation or infection ( $\mathrm{n}=16)$; (2) women with MIAC but without intra-amniotic inflammation ( $n=5)$; (3) women with sterile intra-amniotic inflammation $(n=15)$; and (4) women with intra-amniotic infection $(n=40)$.

\section{Amniotic fluid sample collection}

Amniotic fluid samples were transported to the clinical laboratory in a sterile capped syringe and cultured for aerobic and anaerobic bacteria, including genital mycoplasmas. The clinical tests also included the determination of amniotic fluid white blood cell (WBC) count [90], glucose concentration [91], Gram stain [92], and IL-6 concentration [82].

Table 1: Demographic and clinical characteristics of the study population.

\begin{tabular}{|c|c|c|c|c|c|}
\hline & $\begin{array}{r}\text { Without intra-amniotic } \\
\text { inflammation or } \\
\text { infection }(n=16)\end{array}$ & $\begin{array}{r}\text { With MIAC but } \\
\text { without intra-amniotic } \\
\text { inflammation }(n=5)\end{array}$ & $\begin{array}{l}\text { Sterile intra-amniotic } \\
\text { inflammation }(n=15)\end{array}$ & $\begin{array}{r}\text { Intra-amniotic } \\
\text { infection }(n=40)\end{array}$ & P-value \\
\hline Maternal age, years ${ }^{a}$ & $21(18-25)$ & $25(21-28)$ & $23(20-26)$ & $22(19-26)$ & 0.4 \\
\hline Body mass index, $\mathrm{kg} / \mathrm{m}^{\mathrm{a}}$ & $29.8(26-39.3)$ & $36.4(23.8-41.7)$ & $26.1(22.8-33.7)$ & $26.3(23.3-32.8)$ & 0.4 \\
\hline Ethnicity ${ }^{\mathrm{b}}$ & & & & & 0.3 \\
\hline African American & $50(8 / 16)$ & $60(3 / 5)$ & $13.3(2 / 15)$ & $50(20 / 40)$ & \\
\hline Hispanic & $37.5(6 / 16)$ & $40(2 / 5)$ & $66.7(10 / 15)$ & $40(16 / 40)$ & \\
\hline Caucasian & $6.3(1 / 16)$ & $0(0 / 0)$ & $13.3(2 / 15)$ & $5(2 / 40)$ & \\
\hline Asian & $0(0 / 0)$ & $0(0 / 0)$ & $0(0 / 0)$ & $2.5(1 / 40)$ & \\
\hline Other & $6.3(1 / 16)$ & $0(0 / 0)$ & $6.7(1 / 15)$ & $2.5(1 / 40)$ & \\
\hline $\begin{array}{l}\text { Gestational age at amniocentesis, } \\
\text { weeks }^{\mathrm{a}}\end{array}$ & $38.8(38.2-39.5)$ & $40.4(40.1-40.6)$ & $39.4(38.7-39.8)$ & $39.9(38.8-40.6)$ & 0.01 \\
\hline Delivery route ${ }^{b}$ & & & & & 0.7 \\
\hline Vaginal & $68.8(11 / 16)$ & $60(3 / 5)$ & $60(9 / 15)$ & $72.5(29 / 40)$ & \\
\hline Cesarean section & $31.2(5 / 16)$ & $40(2 / 5)$ & $40(6 / 15)$ & $27.5(11 / 40)$ & \\
\hline Gestational age at delivery, weeks ${ }^{\mathrm{a}}$ & $38.9(38.3-39.8)$ & $40.6(40.1-40.6)$ & $39.6(38.8-39.9)$ & $39.9(38.9-40.6)$ & 0.05 \\
\hline Birth weight, $\mathrm{g}^{\mathrm{a}}$ & $3487.5(3071.3-3687.5)$ & $3610(3135-3815)$ & $3545(3230-3790)$ & $3440(3145-3670)$ & 0.8 \\
\hline
\end{tabular}

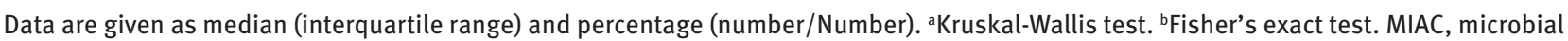
invasion of the amniotic cavity. 


\section{Determination of IL-6 in amniotic fluid}

Amniotic fluid concentrations of IL- 6 were determined by using a sensitive and specific enzyme immunoassay obtained from R\&D Systems (Minneapolis, MN, USA). The IL-6 concentrations were determined by interpolation from the standard curves. The inter- and intra-assay coefficients of variation for IL- 6 were $8.7 \%$ and $4.6 \%$, respectively. The detection limit of the IL- 6 assay was $0.09 \mathrm{pg} / \mathrm{mL}$. The IL- 6 concentrations in amniotic fluid were determined for clinical purposes.

\section{Determination of extracellular ASC in the amniotic fluid}

Concentrations of extracellular ASC in the amniotic fluid were determined using a sensitive and specific enzyme-linked immunosorbent assay (ELISA) kit obtained from LifeSpan Biosciences (Seattle, WA, USA). This ELISA kit was initially validated in our laboratory prior to the execution of this study. Amniotic fluid concentrations of ASC were obtained by interpolation from the standard curve. The interand intra-assay coefficients of variation were $5.0 \%$ and $8.6 \%$, respectively. The sensitivity of the assay was $0.131 \mathrm{ng} / \mathrm{mL}$.

\section{Placental histopathological examination}

Sampling of the placentas was conducted according to established protocols by the Perinatology Research Branch. Five- $\mu$ m-thick sections of formalin-fixed, paraffin-embedded tissue specimens were cut and mounted on SuperFrost ${ }^{\mathrm{TM}}$ Plus microscope slides (Erie Scientific LLC, Portsmouth, NH, USA). After deparaffinization, slides were rehydrated and stained with hematoxylin-eosin. A minimum of five full-thickness sections of chorionic plate, three sections of umbilical cord, and three chorioamniotic membrane rolls from each case were examined by placental pathologists who were blinded to clinical histories and additional testing results. Acute inflammatory lesions of the placenta (maternal and fetal inflammatory responses) were diagnosed according to established criteria, including staging and grading [93-96].

\section{Statistical analysis}

Statistical analyses were performed using the R statistical language and environment (www.r-project.org) and SPSS v19 software (SPSS Inc., IBM Corporation, Armonk, NY, USA). For patient demographics, the Fisher's exact test was used to compare proportions among groups and the Kruskal-Wallis test was used for the comparison of continuous variables among groups. A P-value of $<0.05$ was considered statistically significant. Experimental data was compared between groups using unpaired Wilcoxon tests, and P-values were adjusted across comparisons and the two analytes (IL-6 and ASC) to control the false discovery rate. An adjusted P-value (i.e. q-value) $<0.05$ was considered a significant result. The magnitude of differences was expressed as the difference in means after $\log _{2}$ transformation of the data, to obtain $\log _{2}$ fold changes in concentration. The correlation between ASC and IL-6 levels was assessed via Spearman correlation tests.

\section{Results}

\section{Characteristics of the study population}

The demographic and clinical characteristics of the study population are shown in Table 1 . There were no differences in maternal age, body mass index, ethnicity, delivery route or neonatal birth weight among the study groups (Table 1). Gestational age at amniocentesis was different between the study groups, and such a difference was mostly driven by the study group of MIAC without intraamniotic inflammation that included women who delivered after 40 weeks of gestation (Table 1).

\section{Amniotic fluid ASC concentrations in women with clinical chorioamnionitis at term}

Women with intra-amniotic infection had higher amniotic fluid concentrations of ASC than those without intraamniotic inflammation [intra-amniotic infection: median $27.9 \mathrm{ng} / \mathrm{mL}$ [intraquartile range (IQR) 18.6-69.9 ng/mL] vs. without intra-amniotic inflammation: median $10.2 \mathrm{ng} / \mathrm{mL}$

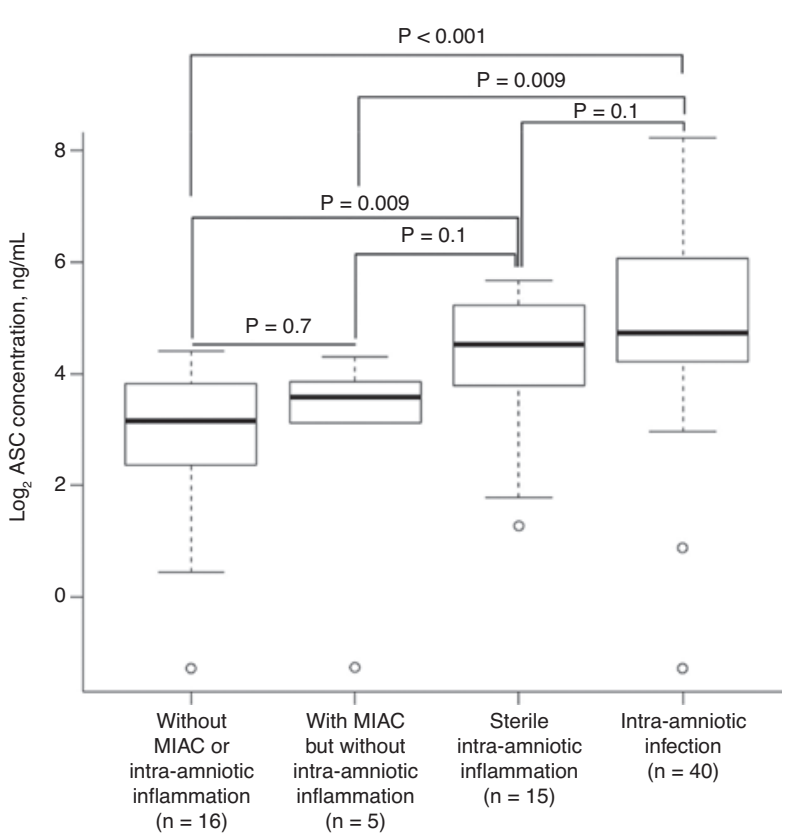

Figure 1: Amniotic fluid ASC concentrations in women with clinical chorioamnionitis at term.

Extracellular ASC ( $\mathrm{ng} / \mathrm{mL}$ ) was measured in amniotic fluid of women with clinical chorioamnionitis at term: without intra-amniotic inflammation $(n=16)$, with microbial invasion of the amniotic cavity (MIAC) but without intra-amniotic inflammation $(n=5)$, with sterile intra-amniotic inflammation ( $\mathrm{n}=15)$, or with intra-amniotic infection $(n=40)$. Data are shown as $\log _{2}$ concentration $(n g / m L)$. 
(IQR 5.3-14.8 ng/mL); P < 0.001] (Figure 1). Women with intra-amniotic infection also had greater amniotic fluid concentrations of ASC than those with MIAC but without intra-amniotic inflammation [intra-amniotic infection: median $27.9 \mathrm{ng} / \mathrm{mL}$ (IQR $18.6-69.9 \mathrm{ng} / \mathrm{mL}$ ) vs. MIAC without intra-amniotic inflammation: median $12.0 \mathrm{ng} / \mathrm{mL}$ (IQR 4.6-17.1 ng/mL); $\mathrm{P}=0.009$ ] (Figure 1). However, no differences were observed between women with intra-amniotic infection and those with sterile intra-amniotic inflammation [intra-amniotic infection: median $27.9 \mathrm{ng} / \mathrm{mL}$ (IQR 18.6-69.9 ng/mL) vs. sterile intra-amniotic inflammation: median $23.0 \mathrm{ng} / \mathrm{mL}$ (IQR 13.2-37.6 ng/mL); P =0.1] (Figure 1).

Women with sterile intra-amniotic inflammation had higher amniotic fluid ASC concentrations compared to those without intra-amniotic inflammation [sterile intra-amniotic inflammation: median $23.0 \mathrm{ng} / \mathrm{mL}$ (IQR 13.2-37.6 $\mathrm{ng} / \mathrm{mL}$ ) vs. without MIAC or intra-amniotic inflammation: median $10.2 \mathrm{ng} / \mathrm{mL}$ (IQR 5.3-14.8 ng/mL); $\mathrm{P}=0.009$ ] (Figure 1). Although women with sterile intraamniotic inflammation tended to have greater amniotic fluid ASC concentrations compared to women with MIAC but without intra-amniotic inflammation, no statistical differences were observed between groups [sterile intra-amniotic inflammation: median $23.0 \mathrm{ng} / \mathrm{mL}$ (IQR $13.2-37.6 \mathrm{ng} / \mathrm{mL}$ ) vs. MIAC without intra-amniotic inflammation: median $12.0 \mathrm{ng} / \mathrm{mL}$ (IQR 4.6-17.1 ng/mL); $\mathrm{P}=0.1$ ] (Figure 1).

\section{Amniotic fluid IL-6 concentrations in women with clinical chorioamnionitis at term}

The amniotic fluid concentration of IL-6 was significantly greater in women with intra-amniotic infection compared to those without intra-amniotic inflammation [intra-amniotic infection: median $22,500 \mathrm{pg} / \mathrm{mL}$ (IQR 7634-57,150 pg/mL) vs. without intra-amniotic inflammation: median $531.8 \mathrm{pg} / \mathrm{mL}$ (IQR 250.6-1073 pg/mL); $\mathrm{P}<0.001$ ] (Figure 2). Women with intra-amniotic infection also had higher concentrations of amniotic fluid IL-6 than those with MIAC but without intra-amniotic inflammation [intra-amniotic infection: median $22,500 \mathrm{pg} / \mathrm{mL}$ (IQR 7634-57,150 pg/mL) vs. MIAC without intra-amniotic inflammation: median $1386 \mathrm{pg} / \mathrm{mL}$ (IQR 350.8$1789 \mathrm{pg} / \mathrm{mL}$ ); $\mathrm{P}<0.001$ ] (Figure 2). Moreover, women with intra-amniotic infection had elevated amniotic fluid IL-6 concentrations compared to those with sterile intra-amniotic inflammation [intra-amniotic infection: median 22,500 pg/mL (IQR 7634-57,150 pg/mL) vs. sterile

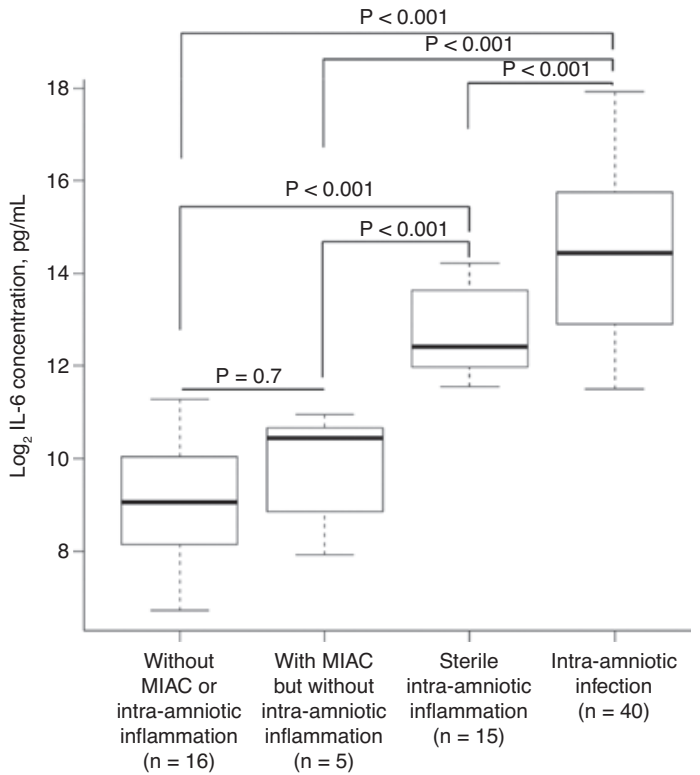

Figure 2: Amniotic fluid IL-6 concentrations in women with clinical chorioamnionitis at term.

IL-6 $(\mathrm{pg} / \mathrm{mL})$ was measured in amniotic fluid of women with clinical chorioamnionitis at term: without intra-amniotic inflammation $(n=16)$, with microbial invasion of the amniotic cavity (MIAC) but without intra-amniotic inflammation $(n=5)$, with sterile intraamniotic inflammation $(n=15)$, or with intra-amniotic infection $(n=40)$. Data are shown as $\log _{2}$ concentration $(\mathrm{pg} / \mathrm{mL})$.

intra-amniotic inflammation: median $5470 \mathrm{pg} / \mathrm{mL}$ (IQR 3392-14,979 pg/mL); $\mathrm{P}<0.001$ ] (Figure 2).

Women with sterile intra-amniotic inflammation had higher amniotic fluid concentrations of IL-6 than those without intra-amniotic inflammation [sterile intraamniotic inflammation: median 5470 pg/mL (IQR 3392$14,979 \mathrm{pg} / \mathrm{mL}$ ) vs. without intra-amniotic inflammation: median 531.8 pg/mL (IQR 250.6-1073 pg/mL); P < 0.001] (Figure 2). In addition, women with sterile intra-amniotic inflammation had greater amniotic fluid concentrations of IL- 6 than those with MIAC but without intra-amniotic inflammation [sterile intra-amniotic inflammation: median $5470 \mathrm{pg} / \mathrm{mL}$ (IQR 3392-14,979 pg/mL) vs. MIAC without intra-amniotic inflammation: median $1386 \mathrm{pg} / \mathrm{mL} \quad$ (IQR $350.8-1789 \mathrm{pg} / \mathrm{mL}$ ); $\quad \mathrm{P}<0.001$ ] (Figure 2).

We next determined whether a correlation existed between intra-amniotic inflammation (as indicated by amniotic fluid IL-6 concentrations) and the concentrations of extracellular ASC in amniotic fluid. We found that there was a significant correlation between the amniotic fluid concentrations of ASC and IL-6 in women with clinical chorioamnionitis at term (Spearman's correlation coefficient of $0.74, \mathrm{P}<0.001$ ) (Figure 3). 


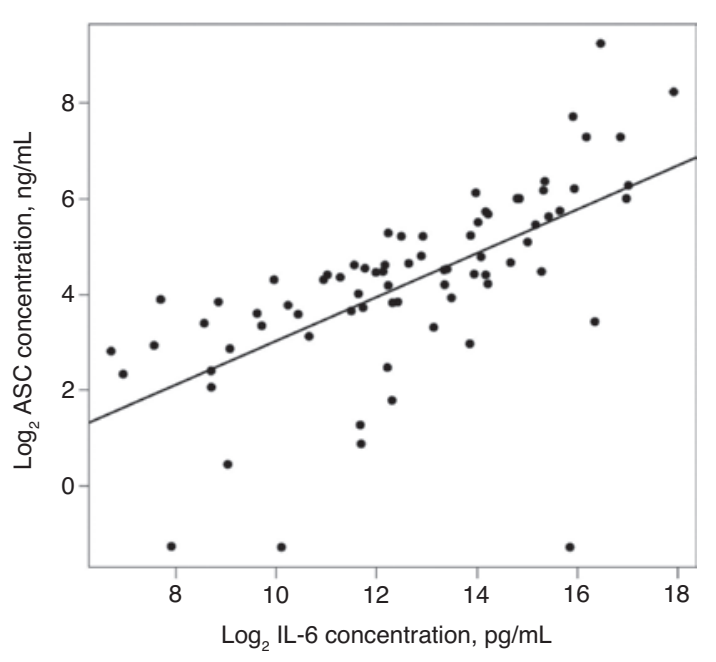

Figure 3: Correlation between ASC and IL-6 amniotic fluid concentrations in women with clinical chorioamnionitis at term. The line represents a linear fit estimating the average $\log _{2}$ ASC concentration as a function of $\log _{2}$ IL-6 concentration.

\section{Acute inflammatory responses in the amniotic cavity and placenta of women with clinical chorioamnionitis at term}

The number of WBCs in amniotic fluid was significantly higher in women with intra-amniotic infection compared to the other three study groups (Table 2). The WBC count was modestly higher in the amniotic fluid of women with sterile intra-amniotic inflammation compared to that of women without intra-amniotic inflammation, or those with MIAC but without intra-amniotic inflammation
(Table 2). Women who delivered with intra-amniotic infection had reduced amniotic fluid glucose concentrations compared to the other study groups (Table 2).

Mild acute maternal (stage 1) and fetal (stage 1) inflammatory responses had a similar prevalence among the study groups; however, moderate acute maternal (stage 2) responses were significantly different (Table 2). Women with intra-amniotic infection had a higher frequency of acute chorioamnionitis and acute necrotizing chorioamnionitis than those with sterile intra-amniotic inflammation (Table 2). Similarly, severe acute fetal (stages 2 and 3) inflammatory responses were more prevalent in women who delivered with intra-amniotic infection (Table 2).

\section{Discussion}

\section{Principal findings}

In clinical chorioamnionitis at term: (1) amniotic fluid concentrations of ASC (extracellular ASC is indicative of in vivo inflammasome activation) and IL-6 were greater in women with intra-amniotic infection than in those without intra-amniotic inflammation, regardless of the presence of MIAC; (2) amniotic fluid concentrations of ASC and IL-6 were also higher in women with sterile intra-amniotic inflammation than in those without intra-amniotic inflammation, regardless of the presence of MIAC; (3) amniotic fluid concentrations of IL-6, but not ASC, were more elevated in women with intra-amniotic infection than in those with sterile intra-amniotic inflammation; (4) a

Table 2: White blood cell counts and glucose concentrations in amniotic fluid and the placental histopathology of the study population.

\begin{tabular}{|c|c|c|c|c|c|}
\hline & $\begin{array}{r}\text { Without intra-amniotic } \\
\text { inflammation or } \\
\text { infection }(n=16)\end{array}$ & $\begin{array}{r}\text { With MIAC but } \\
\text { without intra-amniotic } \\
\text { inflammation }(n=5)\end{array}$ & $\begin{array}{l}\text { Sterile intra-amniotic } \\
\text { inflammation }(n=15)\end{array}$ & $\begin{array}{r}\text { Intra-amniotic } \\
\text { infection }(n=40)\end{array}$ & P-value \\
\hline White blood cell count, cells $/ \mathrm{mm}^{\mathrm{a}}$ & $2(0-5.5)^{c}$ & $2(0-3)$ & $5(1-27.5)$ & $560(57.5-1373.8)$ & $<0.001$ \\
\hline Amniotic fluid glucose, $\mathrm{mg} / \mathrm{dL}^{\mathrm{a}}$ & $9(5.8-17)$ & $10(9-12)$ & $9(8-11.5)$ & $5(1-9)$ & 0.001 \\
\hline \multicolumn{6}{|l|}{ Acute maternal inflammatory response } \\
\hline Stage 1 (acute subchorionitis) $^{\mathrm{b}}$ & $21.4(3 / 14)^{d}$ & $40(2 / 5)$ & $42.9(6 / 14)^{c}$ & $26.3(10 / 38)^{\mathrm{d}}$ & 0.6 \\
\hline Stage 2 (acute chorioamnionitis) $^{\mathrm{b}}$ & $14.3(2 / 14)^{d}$ & $0(0 / 5)$ & $14.3(2 / 14)^{c}$ & $47.4(18 / 38)^{\mathrm{d}}$ & 0.01 \\
\hline $\begin{array}{l}\text { Stage } 3 \text { (acute necrotizing } \\
\text { chorioamnionitis) }^{\mathrm{b}}\end{array}$ & $0(0 / 14)^{d}$ & $0(0 / 5)$ & $0(0 / 14)^{c}$ & $13.2(5 / 38)^{d}$ & 0.3 \\
\hline \multicolumn{6}{|l|}{ Acute fetal inflammatory response } \\
\hline $\begin{array}{l}\text { Stage } 1 \text { (acute phlebitis/ } \\
\text { chorionic vasculitis) }\end{array}$ & $21.4(3 / 14)^{d}$ & $40(2 / 5)$ & $28.6(4 / 14)^{c}$ & $34.2(13 / 38)^{d}$ & 0.5 \\
\hline Stage 2 (acute arteritis) $^{\mathrm{b}}$ & $7.1(1 / 14)^{\mathrm{d}}$ & $0(0 / 5)$ & $0(0 / 14)^{c}$ & $23.7(9 / 38)^{d}$ & 0.1 \\
\hline Stage 3 (necrotizing funisitis) $^{\mathrm{b}}$ & $0(0 / 14)^{d}$ & $0(0 / 5)$ & $0(0 / 14)^{c}$ & $7.9(3 / 38)^{d}$ & 0.6 \\
\hline
\end{tabular}

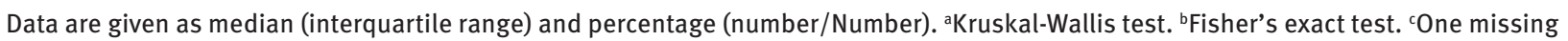
data. ${ }^{\mathrm{d} T}$ Two missing data. MIAC, microbial invasion of the amniotic cavity. 
positive and significant correlation was observed between amniotic fluid concentrations of ASC and IL-6; (5) no differences were observed in amniotic fluid ASC and IL-6 concentrations between women with and without MIAC in the absence of intra-amniotic inflammation; (6) women with intra-amniotic infection had elevated WBC counts and reduced glucose levels in amniotic fluid compared to the other three study groups; and (7) women with intraamniotic infection presented higher frequencies of acute maternal and fetal inflammatory responses in the placenta than those with sterile intra-amniotic inflammation.

\section{In vivo evidence of inflammasome activation in clinical chorioamnionitis at term with intra-amniotic infection}

First, we showed that women with clinical chorioamnionitis at term and intra-amniotic infection had the highest amniotic fluid concentrations of extracellular ASC, which coincides with the most elevated concentrations of IL-6 (i.e. intra-amniotic inflammation). These results are in line with a previous report indicating that women with clinical chorioamnionitis at term and intra-amniotic infection have higher amniotic fluid concentrations of IL-1 $\beta$ - the main product of inflammasome activation [97] - than those without intra-amniotic inflammation [46]. Recently, it was reported that the chorioamniotic membranes from women who underwent labor at term with acute histologic chorioamnionitis, a placental lesion strongly associated with intra-amniotic infection [21, 93, 94, 98-107] and clinical chorioamnionitis at term [85] had (1) elevated mRNA and protein levels of NLRP3 and NLRC4 (i.e. inflammasome sensor molecules), (2) increased expression and amounts of active caspase-1, (3) high concentrations of mature IL-1 $\beta$, and (4) enhanced inflammasome assembly (i.e. ASC/caspase-1 complexes), compared to those without this placental lesion [53, 54]. Furthermore, genital mycoplasmas, the most common microorganisms found in women with clinical chorioamnionitis at term and intra-amniotic infection [40, 85, 108], are capable of activating the inflammasome pathway in murine macrophages [109]. Together, these findings indicate that the inflammasome is involved in the mechanisms that lead to microbial-associated intra-amniotic inflammation in women with clinical chorioamnionitis at term.

Women with clinical chorioamnionitis at term and intra-amniotic infection have high numbers of amniotic fluid immune cells [108], which are more likely to be of maternal origin or a mixture of both fetal and maternal neutrophils [110]. These neutrophils actively participate in the mechanisms of host defense in the amniotic cavity by releasing cytokines [108] and anti-microbial molecules [111-113], performing phagocytosis [114], and forming neutrophil extracellular traps $[115,116]$. In addition, women with clinical chorioamnionitis at term and intra-amniotic infection present severe acute inflammatory lesions in the placenta [40, 46, 85, 117], suggesting that both amniotic fluid neutrophils and the chorioamniotic membranes are a source of extracellular ASC in the amniotic cavity.

\section{In vivo evidence of inflammasome activation in clinical chorioamnionitis at term with sterile intra-amniotic inflammation}

In the current study, we reported that women with clinical chorioamnionitis at term and sterile intra-amniotic inflammation had higher amniotic fluid concentrations of extracellular ASC than those without intra-amniotic inflammation. These results are consistent with a previous study demonstrating that women with clinical chorioamnionitis and sterile intra-amniotic inflammation had higher amniotic fluid concentrations of IL-1 $1 \beta$ than those without intra-amniotic inflammation [46]. In addition, women with clinical chorioamnionitis at term had elevated concentrations of high mobility group box (HMGB) 1 [118], a prototypical alarmin $[119,120]$, whose intra-amniotic administration leads to preterm labor and birth in mice [121]. Importantly, the inoculation of the chorioamniotic membranes with this alarmin induces inflammasome activation [122]. Therefore, we suggested that, in the context of sterile intra-amniotic inflammation, the mechanisms leading to term and premature labor involve the inflammasome [52-57, 123]. Herein, we provided further evidence supporting our hypothesis by showing that there is inflammasome activation in the setting of sterile intra-amniotic inflammation in women with clinical chorioamnionitis at term.

\section{Intra-amniotic infection vs. sterile intra-amniotic inflammation in clinical chorioamnionitis at term}

Amniotic fluid ASC concentrations were comparable between women with intra-amniotic infection and sterile intra-amniotic inflammation, confirming that both inflammatory responses are similar in nature [46]. This is consistent with previous studies showing that the inflammasome can be activated by both microbes [59, 124-134] and alarmins [135-143]. However, sterile signals generate weaker and delayed inflammasome-dependent inflammatory responses compared to those triggered by microbial 
signals [144]. The latter findings provide an explanation as to why, herein, women with clinical chorioamnionitis at term and sterile intra-amniotic inflammation had lower amniotic fluid IL-6 concentrations and a reduced number of amniotic fluid leukocytes compared to those with intraamniotic infection. Consistently, women with clinical chorioamnionitis at term and sterile intra-amniotic inflammation have reduced pro-inflammatory lipid mediators of the 5-lipoxygenase pathway in amniotic fluid compared to those with intra-amniotic infection [145]. Nonetheless, women with sterile intra-amniotic inflammation presented mild/moderate acute inflammatory lesions in the placenta, suggesting that alarmins could cause placental and fetal damage. Collectively, these data suggest that the intra-amniotic inflammatory process initiated by alarmins is milder than that triggered by microbes in women with clinical chorioamnionitis at term; yet, it can be deleterious to the fetus.

\section{Conclusion}

The data presented herein showed that the intra-amniotic inflammatory response, either induced by alarmins or microbes, is characterized by the activation of the inflammasome - as evidenced by elevated amniotic fluid concentrations of extracellular ASC - in women with clinical chorioamnionitis at term. Such a process is similarly observed in both women with intra-amniotic infection and sterile intra-amniotic inflammation, suggesting that both inflammatory processes could cause placental and fetal damage.

Acknowledgments: We thank the physicians and nurses from the Center for Advanced Obstetrical Care and Research and the Intrapartum Unit, as well as the research assistants from the PRB Clinical Laboratory, for their help in collecting samples.

Author contributions: All of the authors have accepted responsibility for the entire contents of this submitted manuscript and approved its submission.

Research funding: This research was supported, in part, by the Perinatology Research Branch (PRB), Division of Intramural Research, Eunice Kennedy Shriver National Institute of Child Health and Human Development, National Institutes of Health, U.S. Department of Health and Human Services (NICHD/NIH/DHHS), and, in part, with federal funds from the NICHD/NIH/DHHS under Contract No. HHSN275201300006C. This research was also supported by the Wayne State University Perinatal Initiative in Maternal, Perinatal and Child Health.
Employment or leadership: None declared.

Honorarium: None declared.

Competing interests: The funding organization(s) played no role in the study design; in the collection, analysis, and interpretation of data; in the writing of the report; or in the decision to submit the report for publication.

\section{References}

1. Newton ER. Chorioamnionitis and intraamniotic infection. Clin Obstet Gynecol 1993;36:795-808.

2. Rouse DJ, Landon M, Leveno KJ, Leindecker S, Varner MW, Caritis SN, et al. The Maternal-Fetal Medicine Units cesarean registry: chorioamnionitis at term and its duration-relationship to outcomes. Am J Obstet Gynecol 2004;191:211-6.

3. Tita AT, Andrews WW. Diagnosis and management of clinical chorioamnionitis. Clin Perinatol 2010;37:339-54.

4. Malloy MH. Chorioamnionitis: epidemiology of newborn management and outcome United States 2008. J Perinatol 2014;34:611-5.

5. Gibbs RS, Blanco JD, St Clair PJ, Castaneda YS. Quantitative bacteriology of amniotic fluid from women with clinical intraamniotic infection at term. J Infect Dis 1982;145:1-8.

6. Gibbs RS, Dinsmoor MJ, Newton ER, Ramamurthy RS. A randomized trial of intrapartum versus immediate postpartum treatment of women with intra-amniotic infection. Obstet Gynecol 1988;72:823-8.

7. Hauth JC, Gilstrap LC, 3rd, Hankins GD, Connor KD. Term maternal and neonatal complications of acute chorioamnionitis. Obstet Gynecol 1985;66:59-62.

8. Mark SP, Croughan-Minihane MS, Kilpatrick SJ. Chorioamnionitis and uterine function. Obstet Gynecol 2000;95(6 Pt 1):909-12.

9. Rojas-Suarez J, Paternina-Caicedo AJ, Miranda J, Mendoza R, Duenas-Castel C, Bourjeily G. Comparison of severity-of-illness scores in critically ill obstetric patients: a 6-year retrospective cohort. Crit Care Med 2014;42:1047-54.

10. Yoder PR, Gibbs RS, Blanco JD, Castaneda YS, St Clair PJ. A prospective, controlled study of maternal and perinatal outcome after intra-amniotic infection at term. Am J Obstet Gynecol 1983;145:695-701.

11. Yancey MK, Duff P, Kubilis P, Clark P, Frentzen BH. Risk factors for neonatal sepsis. Obstet Gynecol 1996;87:188-94.

12. Ladfors L, Tessin I, Mattsson LA, Eriksson M, Seeberg S, Fall 0. Risk factors for neonatal sepsis in offspring of women with prelabor rupture of the membranes at 34-42 weeks. J Perinat Med 1998;26:94-101.

13. Towers CV, Yates A, Zite N, Smith C, Chernicky L, Howard B. Incidence of fever in labor and risk of neonatal sepsis. Am J Obstet Gynecol 2017;216:596 e1-5.

14. Randis TM, Rice MM, Myatt L, Tita ATN, Leveno KJ, Reddy UM, et al. Incidence of early-onset sepsis in infants born to women with clinical chorioamnionitis. J Perinat Med 2018;46:926-33.

15. Rao S, Pavlova Z, Incerpi MH, Ramanathan R. Meconiumstained amniotic fluid and neonatal morbidity in near-term and term deliveries with acute histologic chorioamnionitis and/or funisitis. J Perinatol 2001;21:537-40. 
16. Romero R, Kadar N, Vaisbuch E, Hassan SS. Maternal death following cardiopulmonary collapse after delivery: amniotic fluid embolism or septic shock due to intrauterine infection? Am J Reprod Immunol 2010;64:113-25.

17. Lee J, Romero R, Lee KA, Kim EN, Korzeniewski SJ, Chaemsaithong $\mathrm{P}$, et al. Meconium aspiration syndrome: a role for fetal systemic inflammation. Am J Obstet Gynecol 2016;214:366 e1-9.

18. Brabbing-Goldstein D, Nir D, Cohen D, Many A, Maslovitz S. Preterm meconium-stained amniotic fluid is an ominous sign for the development of chorioamnionitis and for in utero cord compression. J Matern Fetal Neonatal Med 2017;30: 2042-5.

19. Moyo SR, Hagerstrand I, Nystrom L, Tswana SA, Blomberg J, Bergstrom S, et al. Stillbirths and intrauterine infection, histologic chorioamnionitis and microbiological findings. Int J Gynaecol Obstet 1996;54:115-23.

20. Han YW, Fardini Y, Chen C, lacampo KG, Peraino VA, Shamonki $J M$, et al. Term stillbirth caused by oral Fusobacterium nucleatum. Obstet Gynecol 2010;115(2 Pt 2):442-5.

21. Hillier SL, Krohn MA, Kiviat NB, Watts DH, Eschenbach DA. Microbiologic causes and neonatal outcomes associated with chorioamnion infection. Am J Obstet Gynecol 1991;165(4 Pt 1): 955-61.

22. McGregor JA. Maternal and fetal infection. Curr Opin Obstet Gynecol 1991;3:15-23.

23. van Hoeven KH, Anyaegbunam A, Hochster H, Whitty JE, Distant J, Crawford C, et al. Clinical significance of increasing histologic severity of acute inflammation in the fetal membranes and umbilical cord. Pediatr Pathol Lab Med 1996;16:731-44.

24. Grether JK, Nelson KB. Maternal infection and cerebral palsy in infants of normal birth weight. JAMA 1997;278:207-11.

25. Wu YW, Colford JM, Jr. Chorioamnionitis as a risk factor for cerebral palsy: a meta-analysis. JAMA 2000;284:1417-24.

26. Impey L, Greenwood C, MacQuillan K, Reynolds M, Sheil O. Fever in labour and neonatal encephalopathy: a prospective cohort study. BJOG 2001;108:594-7.

27. Wu YW, Escobar GJ, Grether JK, Croen LA, Greene JD, Newman TB. Chorioamnionitis and cerebral palsy in term and near-term infants. JAMA 2003;290:2677-84.

28. Blume HK, Li Cl, Loch CM, Koepsell TD. Intrapartum fever and chorioamnionitis as risks for encephalopathy in term newborns: a case-control study. Dev Med Child Neurol 2008;50:19-24.

29. Soraisham AS, Singhal N, McMillan DD, Sauve RS, Lee SK, Canadian Neonatal N. A multicenter study on the clinical outcome of chorioamnionitis in preterm infants. Am J Obstet Gynecol 2009;200:372 e1-6.

30. Hagberg H, Wennerholm UB, Savman K. Sequelae of chorioamnionitis. Curr Opin Infect Dis 2002;15:301-6.

31. Nelson KB. The epidemiology of cerebral palsy in term infants. Ment Retard Dev Disabil Res Rev 2002;8:146-50.

32. Gilstrap LC, 3rd, Cox SM. Acute chorioamnionitis. Obstet Gynecol Clin North Am 1989;16:373-9.

33. Gibbs RS, Duff P. Progress in pathogenesis and management of clinical intraamniotic infection. Am J Obstet Gynecol 1991;164(5 Pt 1):1317-26.

34. Willi MJ, Winkler M, Fischer DC, Reineke T, Maul H, Rath W. Chorioamnionitis: elevated interleukin- 6 and interleukin- 8 concentrations in the lower uterine segment. J Perinat Med 2002;30:292-6.
35. Lee SE, Romero R, Kim CJ, Shim SS, Yoon BH. Funisitis in term pregnancy is associated with microbial invasion of the amniotic cavity and intra-amniotic inflammation. J Matern Fetal Neonatal Med 2006;19:693-7.

36. Lee SE, Romero R, Jung H, Park CW, Park JS, Yoon BH. The intensity of the fetal inflammatory response in intraamniotic inflammation with and without microbial invasion of the amniotic cavity. Am J Obstet Gynecol 2007;197:294 e1-6.

37. Gotsch F, Romero R, Kusanovic JP, Mazaki-Tovi S, Pineles BL, Erez 0 , et al. The fetal inflammatory response syndrome. Clin Obstet Gynecol 2007;50:652-83.

38. Redline RW. Inflammatory response in acute chorioamnionitis. Semin Fetal Neonatal Med 2012;17:20-5.

39. Mazaki-Tovi S, Vaisbuch E. Clinical chorioamnionitis - an ongoing obstetrical conundrum. J Perinat Med 2016;44:1-4.

40. Romero R, Miranda J, Kusanovic JP, Chaiworapongsa T, Chaemsaithong P, Martinez A, et al. Clinical chorioamnionitis at term I: microbiology of the amniotic cavity using cultivation and molecular techniques. J Perinat Med 2015;43:19-36.

41. Romero R, Miranda J, Chaiworapongsa T, Chaemsaithong P, Gotsch F, Dong Z, et al. A novel molecular microbiologic technique for the rapid diagnosis of microbial invasion of the amniotic cavity and intra-amniotic infection in preterm labor with intact membranes. Am J Reprod Immunol 2014;71:330-58.

42. Combs CA, Gravett M, Garite TJ, Hickok DE, Lapidus J, Porreco R, et al. Amniotic fluid infection, inflammation, and colonization in preterm labor with intact membranes. Am J Obstet Gynecol 2014;210:125 e1-15.

43. Romero R, Miranda J, Chaiworapongsa T, Korzeniewski SJ, Chaemsaithong P, Gotsch F, et al. Prevalence and clinical significance of sterile intra-amniotic inflammation in patients with preterm labor and intact membranes. Am J Reprod Immunol 2014;72:458-74.

44. Romero R, Miranda J, Chaiworapongsa T, Chaemsaithong P, Gotsch F, Dong Z, et al. Sterile intra-amniotic inflammation in asymptomatic patients with a sonographic short cervix: prevalence and clinical significance. J Matern Fetal Neonatal Med 2015;28:1343-59.

45. Romero R, Miranda J, Chaemsaithong P, Chaiworapongsa T, Kusanovic JP, Dong Z, et al. Sterile and microbial-associated intra-amniotic inflammation in preterm prelabor rupture of membranes. J Matern Fetal Neonatal Med 2015;28:1394-409.

46. Romero R, Chaemsaithong P, Korzeniewski SJ, Tarca AL, Bhatti G, Xu Z, et al. Clinical chorioamnionitis at term II: the intra-amniotic inflammatory response. J Perinat Med 2016;44:5-22.

47. Romero R, Chaemsaithong P, Docheva N, Korzeniewski SJ, Tarca AL, Bhatti G, et al. Clinical chorioamnionitis at term V: umbilical cord plasma cytokine profile in the context of a systemic maternal inflammatory response. J Perinat Med 2016;44:53-76.

48. Romero R, Chaemsaithong P, Docheva N, Korzeniewski SJ, Tarca AL, Bhatti G, et al. Clinical chorioamnionitis at term IV: the maternal plasma cytokine profile. J Perinat Med 2016;44: 77-98.

49. Oppenheim JJ, Yang D. Alarmins: chemotactic activators of immune responses. Curr Opin Immunol 2005;17:359-65.

50. Rubartelli A, Lotze MT. Inside, outside, upside down: damageassociated molecular-pattern molecules (DAMPs) and redox. Trends Immunol 2007;28:429-36. 
51. Lotze MT, Zeh HJ, Rubartelli A, Sparvero LJ, Amoscato AA, Washburn NR, et al. The grateful dead: damage-associated molecular pattern molecules and reduction/oxidation regulate immunity. Immunol Rev 2007;220:60-81.

52. Romero R, Xu Y, Plazyo O, Chaemsaithong P, Chaiworapongsa T, Unkel $R$, et al. A role for the inflammasome in spontaneous labor at term. Am J Reprod Immunol 2018;79:e12440.

53. Gomez-Lopez N, Romero R, Xu Y, Garcia-Flores V, Leng Y, Panaitescu B, et al. Inflammasome assembly in the chorioamniotic membranes during spontaneous labor at term. Am J Reprod Immunol 2017;77:e12648.

54. Gomez-Lopez N, Romero R, Xu Y, Plazyo O, Unkel R, Than NG, et al. A role for the inflammasome in spontaneous labor at term with acute histologic chorioamnionitis. Reprod Sci 2017;24:934-53.

55. Gomez-Lopez N, Romero R, Xu Y, Plazyo O, Unkel R, Leng Y, et al. A role for the inflammasome in spontaneous preterm labor with acute histologic chorioamnionitis. Reprod Sci 2017;24:1382-401.

56. Panaitescu B, Romero R, Gomez-Lopez N, Xu Y, Leng Y, Maymon $E$, et al. In vivo evidence of inflammasome activation during spontaneous labor at term. J Matern Fetal Neonatal Med 2018;31:1-14.

57. Gomez-Lopez N, Romero R, Panaitescu B, Leng Y, Xu Y, Tarca AL, et al. Inflammasome activation during spontaneous preterm labor with intra-amniotic infection or sterile intra-amniotic inflammation. Am J Reprod Immunol 2018:e13049. doi: 10.1111/aji.13049. [Epub ahead of print].

58. Sutterwala FS, Ogura Y, Flavell RA. The inflammasome in pathogen recognition and inflammation. J Leukoc Biol 2007;82: 259-64.

59. Mariathasan S, Monack DM. Inflammasome adaptors and sensors: intracellular regulators of infection and inflammation. Nat Rev Immunol 2007;7:31-40.

60. Franchi L, Eigenbrod T, Munoz-Planillo R, Nunez G. The inflammasome: a caspase-1-activation platform that regulates immune responses and disease pathogenesis. Nat Immunol 2009;10:241-7.

61. Jha S, Ting JP. Inflammasome-associated nucleotide-binding domain, leucine-rich repeat proteins and inflammatory diseases. J Immunol 2009;183:7623-9.

62. Latz E. The inflammasomes: mechanisms of activation and function. Curr Opin Immunol 2010;22:28-33.

63. Schroder K, Tschopp J. The inflammasomes. Cell 2010;140: 821-32.

64. Franchi L, Munoz-Planillo R, Reimer T, Eigenbrod T, Nunez G. Inflammasomes as microbial sensors. Eur J Immunol 2010;40:611-5.

65. Lamkanfi M, Dixit VM. Modulation of inflammasome pathways by bacterial and viral pathogens. J Immunol 2011;187:597-602.

66. Horvath GL, Schrum JE, De Nardo CM, Latz E. Intracellular sensing of microbes and danger signals by the inflammasomes. Immunol Rev 2011;243:119-35.

67. Franchi L, Munoz-Planillo R, Nunez G. Sensing and reacting to microbes through the inflammasomes. Nat Immunol 2012;13:325-32.

68. Rathinam VA, Vanaja SK, Fitzgerald KA. Regulation of inflammasome signaling. Nat Immunol 2012;13:333-42.

69. Franchi L, Nunez G. Immunology. Orchestrating inflammasomes. Science 2012;337:1299-300.
70. Latz E, Xiao TS, Stutz A. Activation and regulation of the inflammasomes. Nat Rev Immunol 2013;13:397-411.

71. Vanaja SK, Rathinam VA, Fitzgerald KA. Mechanisms of inflammasome activation: recent advances and novel insights. Trends Cell Biol 2015;25:308-15.

72. Guo H, Callaway JB, Ting JP. Inflammasomes: mechanism of action, role in disease, and therapeutics. Nat Med 2015;21:677-87.

73. Stutz A, Horvath GL, Monks BG, Latz E. ASC speck formation as a readout for inflammasome activation. Methods $\mathrm{Mol}$ Biol 2013;1040:91-101.

74. Baroja-Mazo A, Martin-Sanchez F, Gomez Al, Martinez CM, Amores-Iniesta J, Compan V, et al. The NLRP3 inflammasome is released as a particulate danger signal that amplifies the inflammatory response. Nat Immunol 2014;15:738-48.

75. Franklin BS, Bossaller L, De Nardo D, Ratter JM, Stutz A, Engels G, et al. The adaptor ASC has extracellular and 'prionoid' activities that propagate inflammation. Nat Immunol 2014;15:727-37.

76. Romero R, Chaemsaithong P, Korzeniewski SJ, Kusanovic JP, Docheva N, Martinez-Varea A, et al. Clinical chorioamnionitis at term III: how well do clinical criteria perform in the identification of proven intra-amniotic infection? J Perinat Med 2016;44:23-32.

77. Oh KJ, Kim SM, Hong JS, Maymon E, Erez O, Panaitescu B, et al. Twenty-four percent of patients with clinical chorioamnionitis in preterm gestations have no evidence of either culture-proven intraamniotic infection or intraamniotic inflammation. Am J Obstet Gynecol 2017;216:604.e1-11.

78. DiGiulio DB, Romero R, Amogan HP, Kusanovic JP, Bik EM, Gotsch $F$, et al. Microbial prevalence, diversity and abundance in amniotic fluid during preterm labor: a molecular and culture-based investigation. PLoS One 2008;3:e3056.

79. DiGiulio DB, Romero R, Kusanovic JP, Gomez R, Kim CJ, Seok KS, et al. Prevalence and diversity of microbes in the amniotic fluid, the fetal inflammatory response, and pregnancy outcome in women with preterm pre-labor rupture of membranes. Am J Reprod Immunol 2010;64:38-57.

80. DiGiulio DB, Gervasi M, Romero R, Mazaki-Tovi S, Vaisbuch E, Kusanovic JP, et al. Microbial invasion of the amniotic cavity in preeclampsia as assessed by cultivation and sequence-based methods. J Perinat Med 2010;38:503-13.

81. DiGiulio DB, Gervasi MT, Romero R, Vaisbuch E, Mazaki-Tovi S, Kusanovic JP, et al. Microbial invasion of the amniotic cavity in pregnancies with small-for-gestational-age fetuses. J Perinat Med 2010;38:495-502.

82. Yoon BH, Romero R, Moon JB, Shim SS, Kim M, Kim G, et al. Clinical significance of intra-amniotic inflammation in patients with preterm labor and intact membranes. Am J Obstet Gynecol 2001;185:1130-6.

83. Chaemsaithong P, Romero R, Korzeniewski SJ, Martinez-Varea A, Dong Z, Yoon BH, et al. A rapid interleukin- 6 bedside test for the identification of intra-amniotic inflammation in preterm labor with intact membranes. J Matern Fetal Neonatal Med 2016;29:349-59.

84. Chaemsaithong P, Romero R, Korzeniewski SJ, Martinez-Varea A, Dong Z, Yoon BH, et al. A point of care test for interleukin- 6 in amniotic fluid in preterm prelabor rupture of membranes: a step toward the early treatment of acute intra-amniotic inflammation/infection. J Matern Fetal Neonatal Med 2016;29:360-7. 
85. Romero R, Chaemsaithong P, Docheva N, Korzeniewski SJ, Kusanovic JP, Yoon BH, et al. Clinical chorioamnionitis at term VI: acute chorioamnionitis and funisitis according to the presence or absence of microorganisms and inflammation in the amniotic cavity. J Perinat Med 2016;44:33-51.

86. Pacora P, Romero R, Erez O, Maymon E, Panaitescu B, Kusanovic JP, et al. The diagnostic performance of the beta-glucan assay in the detection of intra-amniotic infection with Candida species. J Matern Fetal Neonatal Med 2017:1-18. DOI: 10.1080/14767058 .2017.1416083.

87. Musilova I, Bestvina T, Hudeckova M, Michalec I, Cobo T, Jacobsson B, et al. Vaginal fluid interleukin- 6 concentrations as a pointof-care test is of value in women with preterm prelabor rupture of membranes. Am J Obstet Gynecol 2016;215:619 e1-12.

88. Park JY, Romero R, Lee J, Chaemsaithong P, Chaiyasit N, Yoon BH. An elevated amniotic fluid prostaglandin F2alpha concentration is associated with intra-amniotic inflammation/infection, and clinical and histologic chorioamnionitis, as well as impending preterm delivery in patients with preterm labor and intact membranes. J Matern Fetal Neonatal Med 2016;29:2563-72.

89. Musilova I, Andrys C, Drahosova M, Soucek O, Stepan M, Bestvina T, et al. Intraamniotic inflammation and umbilical cord blood interleukin-6 concentrations in pregnancies complicated by preterm prelabor rupture of membranes. J Matern Fetal Neonatal Med 2017;30:900-10.

90. Romero R, Quintero R, Nores J, Avila C, Mazor M, Hanaoka S, et al. Amniotic fluid white blood cell count: a rapid and simple test to diagnose microbial invasion of the amniotic cavity and predict preterm delivery. Am J Obstet Gynecol 1991;165(4 Pt 1):821-30.

91. Romero R, Jimenez C, Lohda AK, Nores J, Hanaoka S, Avila C, et al. Amniotic fluid glucose concentration: a rapid and simple method for the detection of intraamniotic infection in preterm labor. Am J Obstet Gynecol 1990;163:968-74.

92. Romero R, Emamian M, Quintero R, Wan M, Hobbins JC, Mazor $M$, et al. The value and limitations of the Gram stain examination in the diagnosis of intraamniotic infection. Am J Obstet Gynecol 1988;159:114-9.

93. Kim CJ, Romero R, Chaemsaithong P, Chaiyasit N, Yoon BH, Kim YM. Acute chorioamnionitis and funisitis: definition, pathologic features, and clinical significance. Am J Obstet Gynecol 2015;213(4 Suppl):S29-52.

94. Redline RW. Classification of placental lesions. Am J Obstet Gynecol 2015;213(4 Suppl):S21-8.

95. Khong TY, Mooney EE, Ariel I, Balmus NC, Boyd TK, Brundler MA, et al. Sampling and definitions of placental lesions: Amsterdam Placental Workshop Group Consensus Statement. Arch Pathol Lab Med 2016;140:698-713.

96. Romero R, Kim YM, Pacora P, Kim CJ, Benshalom-Tirosh N, Jaiman $\mathrm{S}$, et al. The frequency and type of placental histologic lesions in term pregnancies with normal outcome. J Perinat Med 2018;46:613-30.

97. Netea MG, van de Veerdonk FL, van der Meer JW, Dinarello CA, Joosten LA. Inflammasome-independent regulation of IL-1-family cytokines. Annu Rev Immunol 2015;33:49-77.

98. Blanc WA. Amniotic infection syndrome; pathogenesis, morphology, and significance in circumnatal mortality. Clin Obstet Gynecol 1959;2:705-34.

99. Russell P. Inflammatory lesions of the human placenta: clinical significance of acute chorioamnionitis. Am J Diagn Gynecol Obstet 1979;2:127-37.
100. Blanc WA. Pathology of the placenta and cord in ascending and in haematogenous infection. Ciba Found Symp 1979;77:17-38.

101. Hillier SL, Martius J, Krohn M, Kiviat N, Holmes KK, Eschenbach DA. A case-control study of chorioamnionic infection and histologic chorioamnionitis in prematurity. N Engl J Med 1988;319:972-8.

102. Romero R, Salafia CM, Athanassiadis AP, Hanaoka S, Mazor M, Sepulveda W, et al. The relationship between acute inflammatory lesions of the preterm placenta and amniotic fluid microbiology. Am J Obstet Gynecol 1992;166:1382-8.

103. Redline RW, Faye-Petersen O, Heller D, Qureshi F, Savell V, Vogler C, et al. Amniotic infection syndrome: nosology and reproducibility of placental reaction patterns. Pediatr Dev Pathol 2003;6:435-48.

104. Redline RW. Placental inflammation. Semin Neonatol 2004;9:265-74.

105. Fox H, Sebire NJ. Infections and inflammatory lesions of the placenta. Pathology of the placenta. 3rd ed. Edinburgh: Elsevier Saunders; 2007. p. 303-54.

106. Benirschke K, Burton G, Baergen R. Infectious diseases. Pathology of the Human Placenta. Berlin: Springer; 2012. p. 557-655.

107. Anders AP, Gaddy JA, Doster RS, Aronoff DM. Current concepts in maternal-fetal immunology: recognition and response to microbial pathogens by decidual stromal cells. Am J Reprod Immunol 2017;77:e12623.

108. Martinez-Varea A, Romero R, Xu Y, Miller D, Ahmed Al, Chaemsaithong P, et al. Clinical chorioamnionitis at term VII: the amniotic fluid cellular immune response. J Perinat Med 2017;45:523-38.

109. Marques LM, Rezende IS, Barbosa MS, Guimaraes AM, Martins HB, Campos GB, et al. Ureaplasma diversum genome provides new insights about the interaction of the surface molecules of this bacterium with the host. PLoS One 2016;11:e0161926.

110. Gomez-Lopez N, Romero R, Xu Y, Leng Y, Garcia-Flores V, Miller $D$, et al. Are amniotic fluid neutrophils in women with intraamniotic infection and/or inflammation of fetal or maternal origin? Am J Obstet Gynecol 2017;217:693.e1-16.

111. Espinoza J, Chaiworapongsa T, Romero R, Edwin S, Rathnasabapathy C, Gomez R, et al. Antimicrobial peptides in amniotic fluid: defensins, calprotectin and bacterial/permeabilityincreasing protein in patients with microbial invasion of the amniotic cavity, intra-amniotic inflammation, preterm labor and premature rupture of membranes. J Matern Fetal Neonatal Med 2003;13:2-21.

112. Soto E, Espinoza J, Nien JK, Kusanovic JP, Erez O, Richani K, et al. Human beta-defensin-2: a natural antimicrobial peptide present in amniotic fluid participates in the host response to microbial invasion of the amniotic cavity. J Matern Fetal Neonatal Med 2007;20:15-22.

113. Varrey A, Romero R, Panaitescu B, Miller D, Chaiworapongsa T, Patwardhan $M$, et al. Human $\beta$-defensin-1: a natural antimicrobial peptide present in amniotic fluid that is increased in spontaneous preterm labor with intra-amniotic infection. Am J Reprod Immunol 2018; e13031.

114. Gomez-Lopez N, Romero R, Garcia-Flores V, Xu Y, Leng Y, Alhousseini A, et al. Amniotic fluid neutrophils can phagocytize bacteria: a mechanism for microbial killing in the amniotic cavity. Am J Reprod Immunol 2017;78:e12723. 
115. Gomez-Lopez N, Romero R, Xu Y, Miller D, Unkel R, Shaman M, et al. Neutrophil extracellular traps in the amniotic cavity of women with intra-amniotic infection: a new mechanism of host defense. Reprod Sci 2017;24:1139-53.

116. Gomez-Lopez N, Romero R, Leng Y, Garcia-Flores V, Xu Y, Miller $D$, et al. Neutrophil extracellular traps in acute chorioamnionitis: a mechanism of host defense. Am J Reprod Immunol 2017;77:e12617.

117. Chaiyasit N, Romero R, Chaemsaithong P, Docheva N, Bhatti $G$, Kusanovic JP, et al. Clinical chorioamnionitis at term VIII: a rapid MMP-8 test for the identification of intra-amniotic inflammation. J Perinat Med 2017;45:539-50.

118. Romero R, Chaiworapongsa T, Savasan ZA, Hussein Y, Dong Z, Kusanovic JP, et al. Clinical chorioamnionitis is characterized by changes in the expression of the alarmin HMGB1 and one of its receptors, sRAGE. J Matern Fetal Neonatal Med 2012;25:558-67.

119. Wang H, Bloom O, Zhang M, Vishnubhakat JM, Ombrellino M, Che J, et al. HMG-1 as a late mediator of endotoxin lethality in mice. Science 1999;285:248-51.

120. Harris HE, Raucci A. Alarmin(g) news about danger: workshop on innate danger signals and HMGB1. EMBO Rep 2006;7:774-8.

121. Gomez-Lopez N, Romero R, Plazyo O, Panaitescu B, Furcron AE, Miller D, et al. Intra-amniotic administration of HMGB1 induces spontaneous preterm labor and birth. Am J Reprod Immunol 2016;75:3-7.

122. Plazyo O, Romero R, Unkel R, Balancio A, Mial TN, Xu Y, et al. HMGB1 induces an inflammatory response in the chorioamniotic membranes that is partially mediated by the inflammasome. Biol Reprod 2016;95:130.

123. Strauss JF, 3rd, Romero R, Gomez-Lopez N, Haymond-Thornburg H, Modi BP, Teves ME, et al. Spontaneous preterm birth: advances toward the discovery of genetic predisposition. Am J Obstet Gynecol 2018;218:294-314 e2.

124. Kanneganti TD, Body-Malapel M, Amer A, Park JH, Whitfield J, Franchi L, et al. Critical role for Cryopyrin/Nalp3 in activation of caspase- 1 in response to viral infection and doublestranded RNA. J Biol Chem 2006;281:36560-8.

125. Koo IC, Wang C, Raghavan S, Morisaki JH, Cox JS, Brown EJ. ESX-1-dependent cytolysis in lysosome secretion and inflammasome activation during mycobacterial infection. Cell Microbiol 2008;10:1866-78.

126. Muruve DA, Petrilli V, Zaiss AK, White LR, Clark SA, Ross PJ, et al. The inflammasome recognizes cytosolic microbial and host DNA and triggers an innate immune response. Nature 2008;452:103-7.

127. Thomas PG, Dash P, Aldridge JR, Jr, Ellebedy AH, Reynolds C, Funk AJ, et al. The intracellular sensor NLRP3 mediates key innate and healing responses to influenza $A$ virus via the regulation of caspase-1. Immunity 2009;30:566-75.

128. Allen IC, Scull MA, Moore CB, Holl EK, McElvania-TeKippe E, Taxman DJ, et al. The NLRP3 inflammasome mediates in vivo innate immunity to influenza $A$ virus through recognition of viral RNA. Immunity 2009;30:556-65.

129. Duncan JA, Gao X, Huang MT, O’Connor BP, Thomas CE, Willingham SB, et al. Neisseria gonorrhoeae activates the proteinase cathepsin $\mathrm{B}$ to mediate the signaling activities of the NLRP3 and ASC-containing inflammasome. J Immunol 2009;182:6460-9.

130. Joly S, Ma N, Sadler JJ, Soll DR, Cassel SL, Sutterwala FS. Cutting edge: Candida albicans hyphae formation triggers activation of the Nlrp3 inflammasome. J Immunol 2009;183:3578-81.

131. Ichinohe T, Lee HK, Ogura Y, Flavell R, Iwasaki A. Inflammasome recognition of influenza virus is essential for adaptive immune responses. J Exp Med 2009;206:79-87.

132. Menu P, Vince JE. The NLRP3 inflammasome in health and disease: the good, the bad and the ugly. Clin Exp Immunol 2011;166:1-15.

133. Rathinam VA, Vanaja SK, Waggoner L, Sokolovska A, Becker C, Stuart LM, et al. TRIF licenses caspase-11-dependent NLRP3 inflammasome activation by Gram-negative bacteria. Cell 2012;150:606-19.

134. Clay GM, Sutterwala FS, Wilson ME. NLR proteins and parasitic disease. Immunol Res 2014;59:142-52.

135. Martinon F, Petrilli V, Mayor A, Tardivel A, Tschopp J. Gout-associated uric acid crystals activate the NALP3 inflammasome. Nature 2006;440:237-41.

136. Mariathasan S, Weiss DS, Newton K, McBride J, O'Rourke K, Roose-Girma $M$, et al. Cryopyrin activates the inflammasome in response to toxins and ATP. Nature 2006;440:228-32.

137. Hornung V, Bauernfeind F, Halle A, Samstad EO, Kono H, Rock $\mathrm{KL}$, et al. Silica crystals and aluminum salts activate the NALP3 inflammasome through phagosomal destabilization. Nat Immunol 2008;9:847-56.

138. Dostert C, Petrilli V, Van Bruggen R, Steele C, Mossman BT, Tschopp J. Innate immune activation through Nalp3 inflammasome sensing of asbestos and silica. Science 2008;320:674-7.

139. Cassel SL, Eisenbarth SC, Iyer SS, Sadler JJ, Colegio OR, Tephly LA, et al. The Nalp3 inflammasome is essential for the development of silicosis. Proc Natl Acad Sci USA 2008;105:9035-40.

140. Yamasaki K, Muto J, Taylor KR, Cogen AL, Audish D, Bertin J, et al. NLRP3/cryopyrin is necessary for interleukin-1beta (IL-1beta) release in response to hyaluronan, an endogenous trigger of inflammation in response to injury. J Biol Chem 2009;284:12762-71.

141. Cassel SL, Joly S, Sutterwala FS. The NLRP3 inflammasome: a sensor of immune danger signals. Semin Immunol 2009;21:194-8.

142. Cassel SL, Sutterwala FS. Sterile inflammatory responses mediated by the NLRP3 inflammasome. Eur J Immunol 2010;40:607-11.

143. Leemans JC, Cassel SL, Sutterwala FS. Sensing damage by the NLRP3 inflammasome. Immunol Rev 2011;243:152-62.

144. Bezbradica JS, Coll RC, Schroder K. Sterile signals generate weaker and delayed macrophage NLRP3 inflammasome responses relative to microbial signals. Cell Mol Immunol 2017;14:118-26.

145. Maddipati KR, Romero R, Chaiworapongsa T, Chaemsaithong $\mathrm{P}$, Zhou SL, Xu Z, et al. Lipidomic analysis of patients with microbial invasion of the amniotic cavity reveals up-regulation of leukotriene B4. FASEB J 2016;30:3296-307. 